\title{
Crisis, habitus, and intellectual trajectory
}

\section{Alexander Riley}

\section{OpenEdition}

\section{Journals}

Electronic version

URL: http://journals.openedition.org/ress/433

DOI: $10.4000 /$ ress.433

ISSN: $1663-4446$

\section{Publisher}

Librairie Droz

\section{Printed version}

Date of publication: 1 March 2004

Number of pages: $307-314$

ISBN: 2-600-00941-8

ISSN: 0048-8046

Electronic reference

Alexander Riley, "Crisis, habitus, and intellectual trajectory », Revue européenne des sciences sociales [Online], XLII-129 | 2004, Online since 06 November 2009, connection on 20 April 2019. URL : http:// journals.openedition.org/ress/433; DOI : 10.4000/ress.433 
Alexander RILEY

\section{CRISIS, HABITUS, AND INTELLECTUAL TRAJECTORY}

How and how much should biographical events and details from a thinker's life matter in understanding his/her intellectual work? This is a venerable question to which we still do not have many satisfactory answers, despite the efforts of many. Some still argue for purely internalist readings of intellectual projects, unspoiled by information about the thinker's history and position in society, though most would now acknowledge with Karl Mannheim the need to recognize the rooting of an intellectual work and indeed the entire exuve of an intellectual in sociological as well as «epistemological and noological» fields (Mannheim 1936: 287). But once we advance past this still rather perfunctory level of analysis, more refined theoretical tools for examining the intellectual trajectory of a thinker are difficult to come by.

One of the most intriguing of Philippe Besnard's numerous contributions to deciphering the meaning of the work of Emile Durkheim (1982) argues that a close interrogation of the personal and intellectual biography of Durkheim makes apparent something not so clearly evident in the trajectory of his work if it is approached in a purely internalist manner. 'Durkheim the sociologist of anomie' is accepted uncritically by many commentators, who point to the importance of $L e$ suicide both in Durkheim's career and in the establishment of a properly sociological methodology and insinuate that his entire eeuvre should be read as a treatment of anomic conditions of modernity (Besnard 1982: 46-7). Besnard acknowledges that such a reading seems to make sense if anomie is understood as a general crisis of «consensus dans les sociétés modernes,» but he suggests this is a misusage of a concept Durkheim had used far more precisely. In Le suicide and elsewhere (most specifically in L'éducation morale), Durkheim categorized morality as having two distinct elements, one involving integration into the group, the second involving discipline or moral regulation of desires. In both the lectures on education and in the Formes élémentaires, Durkheim points to the necessity of addressing integration, the lack of which creates not anomie but egoism, rather than regulation as the primary task for those who would morally fortify modern society. The attention to anomie in Durkheim's theoretical agenda is in fact shortlived, spanning only essentially the last period of his work on Le suicide. Besnard demonstrates convincingly that the stronger theme of egoism occupies more pages in the work and suggests that this work was «concu et rédigé en deux temps,» one spanning from the early scholarly career of Durkheim, the other (the one in which anomie becomes more important) fitting more or less into the summer and fall of 1896 and the winter of 1897 (Besnard 1982: 48-9).

So how do we explain the apparent disappearance of anomie as a concern in Durkheim's theoretical project once the work on suicide was published? Besnard's 
suggestion is highly instructive. We should note that events in Durkheim's own life indicate a period of profound anomie experienced in 1896 (brought on by the deaths of his brother-in-law, i.e., Marcel Mauss' father, and of his own father; Durkheim's naming to the chair in 'science sociale' at Bordeaux; the weathering of powerful criticisms of his intellectual agenda from his colleagues), which occurs at the same moment in his intellectual career in which he is most directly dealing with the concept of anomie in his work (Besnard 1982: 51). Early the next year, he publishes Le suicide and then in rather short order adopts the intellectual position that, in his own words, «[d]ans le principe, tout est religieux.» From that point, his personal life settles into a stable monotony, religion becomes the focus of his research, and anomie effectively disappears (Besnard 1982: 52).

Besnard's intervention is certainly intended only as a modest contribution to the reading of Durkheim's theoretical project, and he makes no broader claims regarding a research program for the sociology of intellectual trajectory and production. In his analysis, however, we find interesting grounds for the construction of a broader project. At least two larger questions arise after an examination of Besnard's sociobiographical/exegetical effort: how much do crisis experiences in an intellectual's life reflect on the meaning and trajectory of his work, and is there perhaps a means of thinking more systematically, that is, less individualistically, about the phenomenon of crisis as a conditioning factor in the intellectual's life and work? This first question is now and again taken up in intellectual biographies, but few have tried to think of crisis as something that affects intellectual work in ways that can be understood and classed via reference to other aspects of the individual's social history and that might be explored as a general category in the sociology of intellectual production in the same way as we study e.g., formation in educational institutions. For this reason, it remains to this point a concept limited by psychologistic models of understanding, seemingly foreign to sociological application. Besnard's analysis strongly suggests that central pieces of Durkheim's intellectual agenda and evolution are not fully comprehensible without the category of crisis as an element in the social history that constitutes Durkheim as an intellectual. In what follows, I will make some suggestions as to how to extend these useful observations about Durkheim to the sociology of intellectual production more broadly conceived.

Arguably the most important recent effort to examine intellectual work and trajectories in ways extending beyond the internalist and psychologistic is that of Pierre Bourdieu. His category of habitus is an attempt to nuance otherwise too rigid questions of the distinction between social reproduction and individual agency, and it presents some massive potential gains for the project of making sense of intellectual trajectory sociologically. Habitus is, in Bourdieu's remaking of the conventional sociological categories of agency and structure, the substitute for the first of those two notions, while structure becomes field in his model. The most important difference between his categories and the ones being replaced is that both habitus and field are fundamentally relational categories. The habitus ${ }^{1}$ is a

We note in passing that the category is hardly entirely new in Bourdieu's usage. Marcel Mauss used the same Latin term in his essay «Notion de technique du corps » to identify the same kind of socially determined set of «habitudes » that predispose individuals in certain ways, though in the context of Mauss's article, the predispositions consist specifically of body techniques and positions (Mauss 1950: 368-9). 
durably installed generative principle of regulated improvisations...a practical sense which reactivates the sense objectified in institutions...[the] immanent law, lex insita, inscribed in bodies by identical histories, which is the precondition not only for the coordination of practices but also for practices of co-ordination (Bourdieu 1990: 57-59).

It acts as a set of predispositions to action on the part of individuals socialized in what Bourdieu calls objectively identical social conditions that make inevitable certain trajectories for those actors when properly combined with the specific institutional structures whose logic is encoded in them. The habitus, in brief, permits the sociologist to escape completely from the language of the radically unsocial individual and to read what is in more conventional accounts described in the vague language of individual will or whim as fundamentally social.

But there is a certain predisposition of the category itself as Bourdieu wields it to a sociological determinism that downplays situational and experiential nuance in the cultural production and tends rather to a reduction of such production to a reified calculus in which structure creates habitus, which determines practices, which in turn reproduce the same structures. Although Bourdieu generally rejected such a reading of his theory, at times his response was scarcely convincing ${ }^{2}$ and the entirety of his empirical work tends quite clearly in this determinist direction. Part of the problem lies in the fact that, in some of that work, and most notably in his one book-length study of intellectual production (Bourdieu 1988), he seems to understand the sociology of intellectual production as a tool for reading the political position-takings of intellectuals much more than as a method for understanding the overall lived intellectual trajectory of those individuals ${ }^{3}$. Elsewhere, on the occasions when he attempts to analyze sociologically the production of specific intellectuals (Bourdieu 1988b; 1993), those projects are read as the inevitable outcomes of the marginal social position occupied by their authors.

It might however be possible to propose a modified definition of habitus that would avoid this determinism while not removing itself from the realm of sociology altogether. This involves retaining the notion of habitus as a fundamentally relationally-generated set of predispositions, but one that is not determined and defined in an uncomplicated manner by static macro-social grids in the way Bourdieu suggests, precisely because events not encompassed by such a grid, including crises, contribute powerfully to its construction. One can discern and define a habitus for an intellectual or a group of intellectuals and utilize it to understand trajectories taken in the work and lives of those intellectuals, while yet refusing to make the habitus a product of a stock arrangement of easily defined macro-structures and institutions. One simply cannot be so quick to presume from the «normal» categories of conventional sociology (e.g., social class, generation) that individuals who share membership in one or more of

See, for example, Bourdieu and Wacquant 1992: 135-6, where Bourdieu at one and the same time denies «mechanical models» of this kind and yet refers to himself as a «hyperdeterminist.»

3 He has summarized the project of Homo Academicus as an effort « to account, as completely as possible, for the crisis of May ' 68 and, at the same time, to put forth some of the elements of an invariant model of crises or revolutions,» which is something not so subtly different from an effort to map intellectual production itself sociologically (Bourdieu and Wacquant 1992:89). 
these categories therefore share the same objective habitus. The notion of habitus must be diversified and complicated by an understanding that the formative experiences of individuals, while always deeply social, are only at best very rarely and perhaps never objectively identical, and indeed crises or radical changes in an individual's life of the kind Besnard reveals surrounding Durkheim's treatment of anomie must be theorized as a constitutive part of a habitus. So, Bourdieu is doubtless correct when he argues, for example, that university institutions and faculties attempt to produce and recruit students with a specific habitus who have become generalized social actors molded to fit into a particular social network, but we would add that they likely never fully succeed in this task, as the habitus of specific individuals is informed by social networks and experiences beyond those of that institution alone (Bourdieu 1988: 56-57). For a broad mapping of intellectual positions along axes of public political position-taking like Bourdieu's, one may perhaps safely overlook nuances and reduce differences to fit the model. But if one is centrally concerned with the intellectual production itself in its always highly complex relationship to the existential lived trajectory of its producer, one is required to be more attentive to these differences.

Jean-Paul Sartre's existentialist critique of vulgar Marxist attempts to understand intellectual production is instructive here. While attempting to integrate Marxist sociological principles dialectically into existentialist analysis, Sartre vehemently rejects the kind of «lazy Marxism» that would, for example, reduce the poet Paul Valéry to an abstract cipher for the socio-economic class from which he springs:

We see Valéry's ideology as the concrete, unique product of an existent who is characterized in part by his relations with idealism but who must be interpreted in his particularity and first of all in terms of the concrete group from which he has sprung. This in no way means that his relations do not include those of his environment, of his class, etc., but only that we grasp them a posteriori by observation and in our attempt to totalize the sum of possible knowledge on this question. Valéry is a petit bourgeois intellectual, no doubt about it. But not every petit bourgeois intellectual is Valéry... Marxism lacks any hierarchy of mediations that would permit it to grasp the process that produces the person and his product inside a class and within a given society at a given historical moment...Existentialism... intends... to find mediations that allow the concrete individual - the particular life the real and dated conflict, the person - to emerge from the background of the general contradictions of productive forces and relations of production (Sartre 1963: 5557).

Histories, while always social, are also distinct enough to merit closer attention to the details that contribute to significant differences in such predispositions, especially in such cases when the product being examined (intellectual work) is defined by nuance and subtle distinction from the start.

Sartre's three attempts to understand particular bodies of intellectual production (his studies of Baudelaire, Genet and Flaubert) offer useful correctives to the limits of reductionist models of the habitus. In these studies, which in many ways defy disciplinary categorization inasmuch as they incorporate elements of sociology, intellectual history, psychoanalysis and conventional biography, Sartre argues that «a man is never an individual»; he is instead a «universal singular,» that is, «[u]niversal by the singular universality of human history, 
singular by the universalizing singularity of his projects» (Sartre 1981: ix). In keeping in mind this dialectical relationship between the universal and the singular in the project, Sartre is able to explore the effect of concrete historical and social conditions on the formation of the intellectual personality while also recognizing a certain freedom of the intellectual to select from various possible trajectories, a selection that is always affected by relations or events that are eminently social but not reducible to determination by those relations. In his analysis of Baudelaire (Sartre 1963a), for example, Sartre emphasizes the importance of various family interactions and networks but stops short of arguing that they inevitably lead to specific outcomes in the work, instead suggesting possibilities presented by them that may or may not be followed through by the individual.

However, Sartre's approach to the study of intellectual production treats crisis basically from within a psychoanalytic framework; i.e., as something that occurs in childhood. So, for example, the entirety of the crisis experience that makes of Jean Genet the particular kind of writer he is takes place in childhood and early adolescence, «between the ages of ten and fifteen»; all of his later life is essentially the realization of the effects of this primordial crisis experience (Sartre 1963b: 61). Likewise, much emphasis is placed on Flaubert's childhood difficulties with language and other early crises while adult life consists largely of a working out of the consequences of these earlier crises. Additionally, Sartre makes no real effort to establish a framework of broad categories of crisis, contenting himself with the particular crises relevant in the lives of the specific individuals he is studying. The notion of crisis in intellectual trajectories clearly must be defined more broadly than this and it must account for crises experienced throughout the life span insofar as they affect intellectual trajectory. Arpad Szakolczai's approach to the reading of bodies of sociological and philosophical work considers work and life inseparable, and he argues that we need new methodological tools to adequately account for the meaning the two produce together. He points us to the notion of the 'life-work' as a project that is both research problem as documented in intellectual work and lived engagement with existential questions that extend from and are inseparable from the research problem. He understands intellectual production as centered on the ritualistic fabrication and internalization of symbols. The key concept he uses to understand how intellectuals engage these ritualistic processes is that of the experience, which Szakolczai defines, following Victor Turner via Wilhelm Dilthey, in the sense of its Latin etymology as «trial, proof, experiment, peril, danger and testing» (Szakolczai 1998: 22). Experiences which are undergone by intellectuals are of various types (e.g., childhood experiences, reading experiences, reflexive experiences), but all share the fundamental status of rites of passage, i.e., moments of lived reality in which an individual moves through a liminal phase of transformation with the aid of a social network of «masters of ceremonies » that entails at its conclusion a change in the individual's mode of being (Szakolczai 1998: 23-33).

In borrowing the analytical tools that Turner had formulated as a response to the structural functionalist stranglehold on the discipline of anthropology, Szakolczai likewise offers the sociology of intellectual production a powerful means to respond to reductionist structuralist methods. This notion of experience as a sort 
of modern rite of passage $\mathrm{e}^{4}$ offers us another useful tool with which to read intellectual production and trajectory. Indeed, it provides a careful way to discuss sociologically the production of intellectual knowledge and projects in a manner that is attentive to both existential, micro-situations and to structural factors. The reading experience is in his view one of the more important and systematic of these experiences on which interpreters of an intellectual's trajectory should concentrate. It is a singularity, a crisis in the life and thought of the thinker that affects both his/her intellectual direction and his/her life direction in some relatively distinct ways that can be traced. This reading experience may, despite the seemingly narrow specificity of the term, be an encounter with an individual or a particular situation or event as much as it may be with a book. The evidence of the effects of reading experiences is most readily discernible at three sites: acts of «revelation» (rites of passage in which the individual presents himself and his work to public scrutiny such as dissertation defenses, lectures and addresses); acts of «reflexion» (which may appear in summary statements on the project in the form of autobiographies, introductions to important volumes, introductory lectures, etc. and in the form of running commentary on the work that is found in correspondence, interviews and exchanges with critics); and acts of « recognition » (acknowledgements by close acquaintances or colleagues of crucial experiences or events in the lifework of the thinker) (Szakolczai 1998: 33).

But Szakolczai still only gets us part of the way to crisis as a category for the sociology of intellectual production. Crises are clearly a form of experience, but are all experiences crises? This is not clear. A crisis is, at least potentially, the most profound, serious, and unpredictable of experiences, in its effects on both the thinker's work and his life. Durkheim's anomic crisis and its effect on his lifework is arguably different from e.g., his reading experience of Wilhelm Wundt or W. Robertson Smith because it hits him, in a sense, below the surface of his intellectual life and affects his intellectual trajectory in a more subterranean, seismic manner than the encounter of a new intellectual influence. For this reason, the effects of such a crisis on intellectual work, if such exist (and we should be clear to acknowledge that all crises do not inevitably result in discernible effects on intellectual trajectory), are more difficult to trace. There are, for example, no footnotes in Durkheim's works during the period of the crisis to directly document its impact, and indeed he himself may not have been completely aware of the effect in his trajectory that Besnard notes. The excavation of its effects thus requires methodological sensitivity and an omnivorous appetite for sources, as one must be prepared to find evidence of the effects of crisis experiences in the most unexpected of sites.

We might be able to categorize certain more or less typical varieties of crises that affect intellectual trajectory and utilize these categories as a means to marking the similarities to be found in the crisis experiences and subsequent work trajec-

Szakolczai is quick to point out that Turner himself recognized that true rites of passage and liminal experiences perhaps only exist in pure form in pre-literate, non-modern societies (1998: 24-5, 29). While this leads him to a necessary caution in reading too literally the anthropological sense of the terms, it does not by any means negate their potential for increasing understanding of intellectual production. 
tories of different individuals. A preliminary, non-exhaustive collection of categories of crisis might include the following:

- Crises emerging from political struggle (e.g., Durkheim's engagement in the Dreyfus Affair; Foucault's prison activism);

- Crises of founding a new 'school' or discipline (e.g., Durkheim's efforts to establish sociology as a university discipline; Garfinkel's establishment of ethnomethodology within American sociology);

- Crises of religious identity (e.g., Maritain's conversion to Catholicism; Althusser's loss of Catholic faith; Garaudy's conversion to Islam);

- Familial crises, e.g., the death of family members or close friends/colleagues (e.g., the death of Durkheim as effect on the trajectory of Marcel Mauss);

- Crises involving serious illness or disease (e.g., Weber's nervous breakdown; Nietzsche's periods of illness)

These categories might also at some point become a means of integrating what seems a focus on discontinuity (insofar as crisis as a category seems to suggest rupture and irregularity) and a concomitant rejection of the idea of the rational, progressive unfolding of an intellectual trajectory into a more comprehensive understanding of the systematic ways in which crisis contributes to and affects intellectual trajectory. As Michel Foucault often responded to critics who saw his structuralist work in the history of knowledge as promoting a «philosophy of discontinuity » by recalling his efforts in those works to examine deep transformations in systems of knowledge that «dissolve» the apparent discontinuity (see e.g., Foucault 1988: 100), so we might hope through this interrogation of crisis to uncover a logic or logics beneath the turbulent, seemingly chaotic surface. The apparent irregularity of crisis is something to be taken seriously, but such a serious engagement does not necessarily leave one bereft of sociological tools for the integration of crisis into the process of theoretical reconstruction of intellectual habitus. Are there, for example, systematic ways in which crises of religious identity move intellectual trajectories? Does this particular kind of crisis have broadly generalizable effects on e.g., the politics of an intellectual within the realm of scholarly concern? Does it lead to a greater or lesser propensity to engage religious issues as an explicit part of a scholarly program, and perhaps from within a restricted and discernible framework of understanding? These are some of the questions that could be approached empirically once we recognize a certain number of cases and explore them as examples of this kind of experience.

Bucknell University, Lewisburg, USA

atriley@bucknell.edu

\section{BIBLIOGRAPHY}

Besnard Ph., 1982, «L'anomie dans la biographie intellectuelle de Durkheim,» Sociologie et sociétés, $14: 2$, pp. $45-53$.

Bourdieu P., 1990, The Logic of Practice, Stanford: Stanford University Press. 
- 1988, Homo Academicus, Stanford: Stanford University Press.

- 1988b, L'ontologie politique de Martin Heidegger, Paris: Éditions de Minuit.

- 1993, The Field of Cultural Production: Essays on Art and Literature, Cambridge: Polity Press.

- and Wacquant L., 1992, An Invitation to Reflexive Sociology, Chicago: University of Chicago Press.

Foucault M., 1988, Politics, Philosophy, Culture: Interviews and Other Writings 1977-1984, London: Routledge.

Mannheim K., 1936, Ideology and Utopia: An Introduction to the Sociology of Knowledge, New York: Harcourt, Brace and World, Inc.

Mauss M., 1950, Sociologie et anthropologie, Paris: Presses universitaires de France.

Sartre J.-P., 1963, Search for a Method, New York: Alfred A. Knopf.

- 1963a, Baudelaire, Paris: Gallimard.

- 1963b, Saint Genet, New York: Mentor.

- 1981, The Family Idiot: Gustave Flaubert (1821-1857), Chicago: University of Chicago Press, vol. 1.

Szakolczai A., 1998, Max Weber and Michel Foucault: Parallel Lifeworks, London: Routledge. 